\title{
The Global Laboratory of Tobacco Control: Research to Advance Tobacco Cessation in LMICs
}

\author{
Mark Parascandola, and Michele Bloch \\ Tobacco Control Research Branch, Behavioral Research Program, Division of Cancer Control and Population Sciences, National \\ Cancer Institute, 9609 Medical Center Drive, Bethesda, MD, USA
}

\begin{abstract}
$\mathrm{F}$ or over half a century, the U.S. National Cancer Institute (NCI) has supported research on tobacco and health, which has contributed to reductions in tobacco-caused morbidity and mortality in the U.S. But while tobacco use has been slowly declining in most high-income nations, including the US, it has continued to increase in other parts of the globe. Of the 800 million adult men who currently smoke cigarettes, over $80 \%$ are in low- and middle-income countries (LMICs), and these countries will bear an increasing share of the health and economic burden of tobacco use. At the same time, there are additional challenges to implementing tobacco control programs in LMICs, including a diversity of tobacco products, limited capacity and resources for tobacco control, and competing health priorities. While a large body of evidence has been generated around tobacco dependence treatment and other measures in high-income countries, this work is only partly applicable to many LMICs. In this paper we focus on research needs and opportunities around tobacco cessation interventions for LMICs, highlighting four areas: understanding diverse tobacco products, development of low-cost cessation interventions, integrating tobacco cessation into health systems, and understanding tobacco use behaviors across different contexts. Expanding tobacco control research and research capacity in LMICs is crucial to reducing tobacco use and cancer rates worldwide. Furthermore, research conducted in countries around the world can yield important insights for understanding tobacco use behaviors and the effectiveness of tobacco control interventions in the US.
\end{abstract}

'With respect to modifiable risk factors for cancer, there is a consensus that tobacco use remains, by far, the most important at a global level.' (Varmus and Kumar, 2013)

Now is an especially important time to invest in global tobacco control research, particularly research focused on addressing the growing tobacco epidemic in low- and middle-income countries (LMICs). Many countries are introducing new and innovative tobacco control policies but implementing them in different ways and on different timelines. Additionally, many factors within countries, including economic, social, and political conditions, influence patterns of tobacco use and efforts to control it. The global tobacco control environment is also changing rapidly because of new technologies and mass media channels, the introduction of new tobacco products, and economic and policy developments. As a result, the world is now experiencing a series of 'natural experiments' in tobacco control.
While tobacco use has been slowly declining in most high-income countries (HICs), including the US, it has continued to increase in other parts of the globe, shifting from HICs to LMICs. Already, a disproportionate share of the global tobacco burden falls on LMICs, where $84 \%$ of the world's 1.3 billion current smokers reside (WHO, 2015e). And while smoking prevalence remains comparatively low in some regions, such as Sub-Saharan Africa, use is likely to increase because of increased economic development and marketing of manufactured cigarettes, among other factors, if strong tobacco control measures are not in place. Moreover, many LMICs currently have limited capacity for implementing tobacco control and cessation programmes, dealing with the health and economic burdens of tobacco use, and addressing challenges from the tobacco industry.

At the same time, a global movement for tobacco control has developed around the World Health

Address for correspondence: Mark Parascandola, Tobacco Control Research Branch, Behavioral Research Program, Division of Cancer Control and Population Sciences, National Cancer Institute, 9609 Medical Center Drive, Room 3E125 Bethesda, MD 20892-9761 (For UPS/FedEx, use: Rockville, MD 20850).Email: paramark@mail.nih.gov 
Organization (WHO) Framework Convention on Tobacco Control (FCTC), an international treaty aimed at addressing the global tobacco problem, now ratified by over 170 countries. There is a consensus that the available evidence already supports implementation of a package of strong tobacco control policies, such as WHO's MPOWER. (WHO, 2015b). And the WHO's Global Action Plan for the Prevention and Control of NCDs, endorsed by the World Health Assembly, sets a target of a $30 \%$ relative reduction in prevalence of current tobacco use by 2025 (WHO, 2013a). However, to date global tobacco control efforts have focused largely on policy mechanisms to reduce tobacco use with limited attention to interventions for dependence and cessation.

Research, both basic and applied, has been an essential element driving progress in tobacco control and cessation in HICs over the past half century. But while a large body of tobacco control research has been generated in HICs, this work is only partly applicable to the evolving social, economic, and cultural climate of many LMICs, especially in the context of tobacco dependence treatment across countries with diverse health systems, access to medication, tobacco use behaviours, patterns of dependence, and tobacco products. As we will argue further, expanding tobacco control research and research capacity in LMICs is crucial to continued progress towards reducing tobacco use (Yach, Pratt, Glynn, \& Reddy, 2014). Research on tobacco dependence and cessation, from interventions at the individual level to those implemented though broader programs or policies, is essential to this effort, as ambitious targets for reduction in smoking prevalence will require strong actions not only to prevent uptake of tobacco use, but also to help current users to quit. While there are a broad range of research needs to support international tobacco control, in this paper we focus on research needs around tobacco dependence and cessation in LMICs.

\section{Challenges and Opportunities for Tobacco Control Research in LMICs}

Broad, comprehensive tobacco control strategies have been one of the greatest public health successes of the 20th century, as smoking prevalence in HICs has dropped steadily over several decades, with consequent reductions in mortality from lung and other cancers and other diseases (Lopez, Collishaw, \& Piha, 1994). Research has played a key role in this progress. But it took decades to build a community of tobacco control researchers and an evidence base for comprehensive tobacco control research programmes. While studies in the 1950s demonstrated the many adverse health effects of cigarette smoking, little scientific work examined the nature of smoking behaviour, tobacco dependence, or interventions to promote behaviour change until the late 1970s, when researchers experienced in studying other forms of drug abuse applied their methods to the study of cigarette smoking (Paras- candola, 2011). And it was not until the late 1980s and 1990s that large-scale intervention trials (e.g., COMMIT) and demonstration projects (e.g., ASSIST) formally evaluated the impact of multilevel interventions to reduce tobacco use on a population level (National Cancer Institute [NCI], 1991, 2005).

Many LMICs are still in the early stages of the tobacco epidemic, with smoking prevalence remaining high or rising, not having yet reached a peak, and the full impact of tobacco use on morbidity and mortality not yet felt (Lopez et al., 1994; Thun, Peto, Boreham, \& Lopez, 2012). But, LMICs need not follow the trajectory that other countries have historically taken; they have the opportunity to intervene much earlier and make much faster progress in reducing tobacco use. LMICs can benefit from the dramatic advances in global tobacco control of the last 50 years. In addition to the WHO FCTC, there is an extensive global community of tobacco control experts and advocates who have decades of experience enacting and implementing tobacco control policies, programmes, and interventions. There is a strong and growing evidence base to support policies and interventions and a robust global tobacco surveillance system (GTSS) that provides critical data on the scope of the problem of tobacco use and progress in combatting it. Support for smokefree policies, for example, is high in a number of LMICs and smokefree workplaces in LMICs are associated with living in a smokefree home (ITC Project 2012b; Nazar et al., 2014; Obeidat et al., 2015). Perhaps most important, there is broad recognition of the tobacco industry's role in promoting the spread of tobacco use and the importance of protecting tobacco control from the commercial and other interests of the tobacco industry (NCI, 2007; WHO, 2008).

However, expanded research efforts are needed to support implementation of strong, effective tobacco control measures in LMICs. Most of the current evidence on tobacco control measures, particularly cessation interventions, comes from HICs and may not translate well to other contexts (Clinical Practice Guideline Panel, 2008; McRobbie, Raw, \& Chan, 2013). Cessation guidelines from HICs may not be appropriate for some LMICs for a variety of reasons (including accessibility and cost of pharmaceutical treatment, differences in health care settings, and differences in tobacco use behaviours and products). Countries that lack their own cessation guidelines cite a lack of resources or technical support (Raw \& Slevin, 2007). Despite the GTSS, some countries still do not have adequate data on tobacco use and tobacco-related health outcomes (WHO, 2013c). And most LMICs lack the decades of experience and capacity that many HICs have acquired to develop, evaluate, and implement tobacco control interventions (Warner, 2005). As in HICs, research will play a crucial role in developing and implementing tobacco control policies and interventions in LMICs (Leischow, Ayo-Yusuf, \& Backinger, 2013). Additionally, as we discuss later, high tobacco use among health professionals in some countries poses an additional barrier. 
Research in LMICs can yield substantial insights for HICs as well (Glass, 2013). Applying the concept of 'reverse innovation' to global health (Govindarajan \& Trimble, 2012), a case has been made that research and experience acquired in LMICs can benefit HICs, particularly in areas like rural health delivery, application of mHealth technologies, creative problem solving, and health financing (Syed et al., 2012). In the realm of tobacco control, HICs may gain valuable insights from studying innovative policies and interventions pioneered in other countries. For example, the FDA's proposed rule for graphic warning labels on cigarettes in the US relied in part on a body of evidence which comes from countries that have already implemented such measures (US Food and Drug Administration, 2011). In addition, Brazil was one of the first countries to ban misleading descriptors such as 'light' and 'mild' on cigarette packages (2001), and other countries, including the US, followed suit (Blanke \& da Costa e Silva, 2004). Several states in India have banned gutka, a class of packaged tobacco product that was inexpensive and widely available; the effectiveness of this novel approach to reducing tobacco use is still being assessed (WHO, 2015a).

Experience from LMICs may also have relevance for addressing health disparities in HICs. In HICs, exposure to tobacco products and tobacco smoke is increasingly concentrated in low-income populations, among people with working class occupations and those with low levels of education (Barbeau, Krieger, \& Soobader, 2004; Gostin, 2014a; Hajat, Kaufman, Rose, \& Siddiqi, 2010; Lopez et al., 1994). Within LMICs, lower income is usually (though not always) associated with increased tobacco use prevalence as well (WHO, 2014). Studies from HICs show that tobacco companies have targeted low-income and minority populations (Iglesias-Rios \& Parascandola, 2013; Yerger, Przewoznik, \& Malone, 2007); tobacco retailers and retail advertising are more highly concentrated in low-income neighbourhoods (Hillier et al., 2015; Rodriguez, Carlos, Adachi-Mejia, Berke, \& Sargent, 2013; Schneider \& Gruber, 2013); and low socioeconomic status (SES) and the presence of tobacco retailers are negatively associated with smoking cessation (Cano \& Wetter, 2014; Cantrell et al., 2015). Development of low-cost cessation interventions to assist underserved populations in LMICs may also have relevance for HICs.

\section{Promoting Cessation Interventions in LMICs: Research Needs}

A broad range of research needs have been identified to support effective global tobacco control (Leishchow et al., 2013). Four areas are especially relevant to advancing tobacco cessation interventions in LMICs: understanding diverse tobacco products; novel, low-cost cessation interventions; integrating tobacco cessation into health systems; and understanding tobacco use behaviours and effective implementation.

\section{Understanding Diverse Tobacco Products}

A wide range of smoked and smokeless tobacco products with different characteristics are in use around the world, including cigarettes, cigars, bidis, waterpipe tobacco, chewing tobacco, snuff, and gutka, but limited data are available on the properties, modes of use, and health effects of many of these products. In order to develop effective interventions, it is necessary to understand not just the user, but also the product and how it is used (user behaviour, means of nicotine delivery, etc.), a task which is complicated by the diversity of products and user behaviours. Additionally, production, sale, and regulation of tobacco products vary widely across countries and regions. Traditional products in some LMICs may be produced in a local 'cottage industry' or prepared for the user by a street vendor, making it difficult to monitor product composition (National Cancer Institute and Centers for Disease Control and Prevention, 2014).

Understanding particular products can have relevance far beyond the local environment in which they are studied. For example, waterpipe tobacco smoking is increasingly popular among youth in the US and many other countries, and waterpipe cafes are now frequently seen around university campuses in the US and other countries (Maziak et al., 2015). Studies conducted in countries with a long history of waterpipe use have advanced understanding of this products' use and health effects (Al Ali et al., 2015). Nicotine delivery and exposure differs across products also and such differences may be significant for developing effective interventions. (Maziak, Eissenberg, and Ward, 2005; Stanfill et al., 2011). Use of novel products (such as the e-cigarette) can spread very rapidly, outpacing our understanding of their use and health effects. Thus, developing research capacity for and an evidence base on product characteristics, user dependence and behaviour, and health consequences associated with different tobacco products is extremely important to developing effective interventions.

\section{Novel, Low-Cost Cessation Interventions}

For countries with a high smoking prevalence, dramatic reductions in tobacco use will require strong, accessible interventions to help smokers quit. Importantly, cessation by current smokers will have greater near-term benefits in reducing tobacco-related mortality compared with smoking prevention efforts targeted toward younger people (Peto et al., 2000). In addition, tobacco cessation can reduce the number of role models for tobacco use, help promote a tobacco-free norm, and indirectly support prevention of youth tobacco use. Even in countries where quit rates are low and tobacco control policies are relatively weak, such as China, survey data suggest that demand for cessation is high (International Tobacco Control Policy Evaluation Project, 2012a). Research in HICs has demonstrated the efficacy of both population-level approaches, such as mass media campaigns and tobacco quitlines, and 
individual-level approaches, such as providing tobacco dependence medications and behavioural interventions to tobacco users (West et al., 2015).

However, there are substantial challenges to tobacco cessation efforts in LMICs. Despite Article 14 of the FCTC, which promotes national tobacco cessation programmes, many countries, particularly LMICs, still lack tobacco dependence guidelines, services, and training programmes (Kruse et al., 2015; Pine-Abata 2013a;b). Additionally, research is needed to develop and implement effective cessation strategies in resource-poor environments and where access to health care providers may be limited or non-existent. In particular, pharmacotherapies may be unavailable or too expensive to be a feasible intervention, particularly in low-income countries. Additionally, in some low-income countries, smokers rarely have the opportunity to see a health care provider and the health care system's capacity to play a role in cessation may be very limited (Beratarrechea et al., 2014). Thus, cessation support strategies are needed that do not rely on frequent or direct contact with the health care system and can be delivered widely. For example, studies in several countries are assessing the potential for mobile technologies and texting, especially to reach young tobacco users (Fogarty launches mHealth program, 2014). It may also be necessary to tailor interventions to different cultures or environments and to scale them up for broad implementation.

The diversity of tobacco products and use behaviours poses challenges for cessation interventions. For example, strategies for smokeless tobacco cessation have had limited success, as pharmacotherapies found effective in smokers (e.g., nicotine patch, nicotine gum, and bupropion) have generally not had the same success in smokeless tobacco users (National Cancer Institute and Centers for Disease Control, 2014). Similarly, few treatment trials have been conducted for waterpipe smoking, and little research has focused on interventions tailored to waterpipe use or the specific cultural and social conditions that promote it (Ward, Siddiqi, Ahluwalia, Alexander, \& Asfar, 2015; WHO Study Group, 2005).

\section{Integrating Tobacco Cessation Into Health Systems}

In HICs, physicians and other health professionals (particularly those who were younger) were the first to modify their behaviour and call for effective measures to reduce tobacco use, in response to new evidence. (Garfinkel \& Stellman, 1976). But use by health professionals remains an obstacle in many LMICs. In China, for example, 61.3\% of male physicians smoke, a rate only slightly lower than that of men in the general population (66.9\%) (WHO, 2013a). Data from the Health Professional Schools Survey shows that tobacco use prevalence remains above $20 \%$ among health professions students (medicine, dentistry, nursing, and pharmacy) in over half of 80 survey sites across 31 countries, with some sites reporting prevalence over $50 \%$. For most sites, a majority of respondents reported that they thought health professions students should receive tobacco cessation training, but they had not themselves received it (Warren, Jones, Chauvin, \& Peruga, 2008). Additionally, only $63 \%$ of countries ban smoking in health facilities - a missed opportunity to protect patients and staff, and to promote a tobacco-free norm to the public (WHO, 2015c).

There are unique opportunities to integrate tobacco cessation interventions, even basic assessment and advice, into existing public health and health care delivery programmes. Given existing infrastructure around well-established global health priorities such as HIV prevention, TB control, and improving maternal, newborn and child health, finding creative ways to integrate tobacco-related interventions into these activities could substantially expand access to cessation and address the growing global burden of NCDs (Jaacks et al., 2015). Working within existing systems is especially important where there is limited access to medical/health care and a shortage of health professionals. For example, pregnancy is a time when women are very likely to see a health care professional, making maternity care a key opportunity for integration of tobacco control (WHO, 2013b).

NCI's partnership with the US Agency for International Development (USAID) is an example of supporting research projects aimed at integrating tobacco cessation interventions into broader health efforts. NCI provides support to a project in the Philippines evaluating a smoking cessation intervention programme for families of children with tuberculosis and to two projects in Indonesia to reduce adverse birth outcomes by reducing second-hand smoke exposure in the home (National Academies, 2015). These projects are part of the Partnerships for Enhanced Engagement in Research (PEER) programme, through which USAID and other US government agencies support research partnerships between LMIC investigators and scientists funded by the US government.

\section{Understanding Tobacco Use Behaviours and Effective Implementation}

To effectively intervene to reduce tobacco use across the variety of social and cultural settings in LMICs, an understanding of the factors that contribute to tobacco use behaviour is essential. These factors range from individuallevel social interactions to broad cultural, economic, and policy influences. Additionally, applied research on effective implementation of policies, programmes, and interventions is needed to assist in scaling up interventions and evaluating their impact in the field. However, in many LMICs, organised research programmes in fields like health policy analysis, implementation research, and behavioural sciences are currently lacking (Chopra, Munro, Lavis, Vist, \& Bennett, 2008; Erasmus, Orgill, Schneider, \& Gilson, 2014; Gilson \& Raphaely, 2008).

To illustrate, while overall global smoking prevalence is far higher among men than among women $(36.1 \%$ versus $6.8 \%$ in 2012), (WHO, 2015d) the threat of a potential rise in women's tobacco use rates has long been 
recognized (WHO, 1992). Indeed, in some countries that have experienced substantial economic development over the past three decades, particularly in the Eastern Mediterranean region, smoking among women has increased significantly since 1980 (Ng et al., 2014). Even in countries such as India, where the prevalence of smoking has traditionally been low among women, data suggest that smoking is increasing more rapidly among women than men (Goel, Tripathy, Singh, \& Lal, 2014). To develop effective interventions and strategies that address smoking among women, it is important to understand the factors that drive changes in female smoking patterns, including improvements in women's economic status, changing social roles, job- and family-related stress, the breakdown of traditional cultural restraints on women's tobacco use and tobacco marketing targeted to women (Ding et al., 2014; Hitchman \& Fong, 2011; Nichter et al., 2010).

\section{Investment in Building Research Capacity}

In order to tackle these research gaps, there is a need to build sustainable research capacity in LMICs. Large international donors such as the Bill and Melinda Gates Foundation and the Bloomberg Philanthropies have made enormous progress in supporting capacity for tobacco control in LMICs, but their primary focus has been on advocacy for policy change rather than research. At the same time, international global health and development efforts, such as the Global Fund to Fight AIDS, Tuberculosis and Malaria, remain focused on capacity for addressing infectious diseases with limited attention to cigarette smoking and other non-communicable disease risk factors. (Gostin 2014b)

Several organizations have made investments in tobacco control research capacity in LMICs in recent years, including the American Cancer Society, Cancer Research UK, Canada's International Development Research Center, Global Bridges and NCI. In 2014, NCI and Cancer Research UK began working with other leading cancer research organizations around the world with a goal to coordinate and expand investment in tobacco control research and capacity in LMICs (Cox, 2014). While most of NCI's tobacco research portfolio across a wide range of topics is focused on domestic research needs, (Ponder, Jefferson, Backinger, \& Grana, 2007) the institute has also supported innovative international research projects and sought to build research capacity in LMICs. A primary example is the International Tobacco and Health Research and Capacity Building Program, established in 2002 and led by the Fogarty International Center, with support from NCI and the National Institute on Drug Abuse, which supports collaborative research and research capacity building projects that address the burden of tobacco consumption in LMICs (Primack et al., 2006). Each project involves a partnership between investigators in the US or other HICs and scientists and institutions in LMICs. A recent evaluation of the program's first 10 years found that it had a substantial impact on international tobacco control research capacity (Fogarty International Center, 2013). NCI's Center for Global Health was created in 2011 to reduce the global cancer burden by creating sustainable international partnerships, supporting research and scientific training, and disseminating information on best practices for cancer prevention and control (Varmus \& Trimble, 2011). NCI's collaboration with USAID through PEER, described above, is an example of how tobacco cessation intervention research and capacity building can be expanded through partnerships with entities engaged in global health.

\section{Conclusion}

In the 21st century, tobacco is poised to prematurely kill as many as one billion of the world's citizens, primarily in LMICs. In response to this threat, a global tobacco control movement has formed, centred on implementing provisions of the WHO FCTC. As a result, we live in a global laboratory of tobacco control, which can provide insights useful for all countries. Research has established a strong evidence base for tobacco control, but will continue to be critical to make rapid progress, in the US and elsewhere. Of the broad range of research needs necessary to support global tobacco control and FCTC implementation, we have highlighted here several key targets for research investment related to tobacco cessation: better understanding of diverse tobacco products; development and testing of novel, low-cost cessation interventions; integration of tobacco cessation into health systems, including existing global health programmes; and better understanding tobacco use behaviours and effective implementation in different settings. Efforts to increase research capacity and infrastructure are needed in LMICs, where tobacco control capacity is often the weakest. Now is the time to make investments in the research needed to eradicate tobacco use as the leading preventable cause of global cancer mortality and of death and disease worldwide.

\section{Conflicts of Interest}

No funding or conflicts of interest to declare.

\section{References}

Al Ali, R., Rastam, S., Ibrahim, I., Bazzi, A., Fayad, S., Shihadeh, A. L. et al. (2015). A comparative study of systemic carcinogen exposure in waterpipe smokers, cigarette smokers and non-smokers. Tobacco Control, 24(2), 125-127.

Amos, A., Greaves, L., Nichter, M., \& Bloch, M. (2012). Women and tobacco: A call for including gender in tobacco control research, policy, and practice. Tobacco Control, 12, 236-243. Retrieved from http://tobaccocontrol.bmj.com/ content/21/2/236.full.

Barbeau, E. M., Kreiger, N., \& Soobader, M. J. (2004) Working class matters: Socioeconomic disadvantage, race/ethnicity, gender, and smoking in NHIS 2000. American Journal of Public Health, 94, 269-278. 
Beratarrechea, A., Lee, A. G., Willner, J. M., Jahangir, E., Ciapponi, A., \& Rubinstein, A. (2014). The impact of mobile health interventions on chronic disease outcomes in developing countries: A systematic review. Telemedicine Journal and E-Health, 20(1), 75-82.

Blanke, D. D., \& da Costa e Silva, V. (Eds.). (2004). Tobacco control legislation: An introductory guide. (2nd ed.) Geneva: World Health Organization. Retrieved from https://books. google.com/books?id=0LAVl_j1ny4C\&pg=PT175\&lpg= PT175\&dq=brazil+light+low+tar\&source=bl\&ots= m3afH1sXQv\&sig=J7vPIl0J7I1j7jocCHdPUmyCY4g\&hl= en\&sa $=$ X\&ved=0CC0Q6AEwAmoVChMImprEunqxwIV04uSCh1vxQdN\#v=onepage $\& q=$ brazil $\% 20$ light $\%$ 20low\%20tar\&f=false

Cano, M. Á., \& Wetter, D. W. (2014). Socioeconomic status and smoking cessation: Neighborhood context as an underlying mechanism. Texas Heart Institute Journal, 41(3), 309-310.

Cantrell, J., Anesetti-Rothermel, A., Pearson, J. L., Xiao, H., Vallone, D., \& Kirchner, T. R. (2015). The impact of the tobacco retail outlet environment on adult cessation and differences by neighborhood poverty. Addiction, 110(1), 152-161.

Chopra, M., Munro, S., Lavis, J. N., Vist, G., \& Bennett, S. (2008). Effects of policy options for human resources for health: An analysis of systematic reviews. Lancet, 371(9613), 668-674.

Clinical Practice Guideline Treating Tobacco Use and Dependence 2008 Update Panel, Liaisons, and Staff. (2008) A clinical practice guideline for treating tobacco use and dependence: 2008 update. A U.S. Public Health Service report. American Journal of Preventive Medicine, 35(2), 158-176.

Cox, A. (2014 July). International initiative for action and research on tobacco: Opportunities for collaboration with low- and middle-income countries. Presented at the 2014 ASH Scotland Conference. Retrieved from http://www. ashscotland.org.uk/media/6723/13.\%20Alison\%20Cox.pdf.

Ding, D., Gebel, K., Oldenburg, B. F., Wan, X., Zhong, X., \& Novotny, T. E. (2014). An early-stage epidemic: A systematic review of correlates of smoking among Chinese women. International Journal of Behavioral Medicine, 21(4), 653-661.

Erasmus, E., Orgill, M., Schneider, H., \& Gilson, L. (2014). Mapping the existing body of health policy implementation research in lower income settings: What is covered and what are the gaps?. Health Policy and Planning, 2(Suppl 3), iii35-iii50.

Fogarty International Center. (2013). International tobacco and health research and capacity building program review. Retrieved from http://www.fic.nih.gov/About/Staff/PolicyPlanning-Evaluation/Pages/fogarty-program-evaluationtobacco.aspx.

Fogarty launches mHealth program. (2014, January/February). Global Health Matters. Retrieved from http://www.fic.nih. gov/News/GlobalHealthMatters/january-february-2014/ Pages/mhealth-program-launch.aspx.

Garfinkel, L., \& Stellman, S. D. (1976). Cigarette smoking among physicians, dentists and other health professionals, 19591972. CA-A Cancer Journal for Clinicians, 26, 373-375.

Gilson, L., \& Raphaely, N. (2008) The terrain of health policy analysis in low and middle income countries: A review of published literature 1994-2007. Health Policy and Planning, 23(5), 294-307.

Glass, R. L. (2013). JAMA viewpoint: What the United States has to gain from global health research. JAMA: The Journal of the American Medical Association. Retrieved from http:// www.fic.nih.gov/News/Publications/Pages/roger-glass-jamaviewpoint-2013-united-states-global-health.aspx.

Goel, S., Tripathy, J. P., Singh, R. J., \& Lal, P. (2014). Smoking trends among women in India: Analysis of nationally representative surveys (1993-2009). South Asian Journal of Cancer, 3(4), 200-202.

Gostin, L. O. (2014a). Tobacco endgame: The poverty conundrum. Hastings Center Report, 44(3), 10-11.

Gostin, L. O. (2014b). Non-communicable diseases: Health living needs global governance. Nature, 511(7508), 147-149.

Govindarajan, V., \& Trimble, C. (2012). Reverse innovation: Create far from home, win everywhere. Boston: Harvard Business Review Press. Retrieved from http://www.amazon.com/ Reverse-Innovation-Create-From-Everywhere/dp/ 1422157644.

Hajat, A., Kaufman, J. S., Rose, K. M., Siddiqi, A., \& Thomas, J. C. (2010). Do the wealthy have a health advantage? Cardiovascular disease risk factors and wealth. Social Science \& Medicine, 71, 1935-1942.

Hillier, A., Chilton, M., Zhao, Q. W., Szymkowiak, D., Coffman, R., \& Mallya, G. (2015). Concentration of tobacco advertisements at SNAP and WIC stores, Philadelphia, Pennsylvania, 2012. Preventing Chronic Disease, 12, E15.

Hitchman, S. C., \& Fong, G. T. (2011). Gender empowerment and female-to-male smoking prevalence ratios. Bulletin of the World Health Organization, 89(3), 195-202.

Iglesias-Rios, L., \& Parascandola, M. (2013). A historical review of R.J. Reynolds' strategies for marketing tobacco to Hispanics in the United States. American Journal of Public Health, 103(5), e15-27.

International Tobacco Control Policy Evaluation Project. (2012a). ITC China project report findings from the wave 1 to wave 3 surveys (2006-2009). Waterloo, Ontario, Canada: University of Waterloo, and Beijing: Chinese Center for Disease Control and Prevention, Office of Tobacco Control. Retrieved from http://www.itcproject.org/ files/ITC-China-NR-English-web-Dec142012-FINAL.pdf.

International Tobacco Control Policy Evaluation Project. (2012b). Smoke-free Policies: ITC Cross-country Comparison Report. Waterloo, ON: University of Waterloo. Retrieved from http://www.itcproject.org/resources/view/1145.

Jaacks, L. M., Ali, M. K., Bartlett, J., Bloomfield, G. S., Checkley, W., Gaziano, T. A. et al. (2015 August 25). Global noncommunicable disease research: Opportunities and challenges. Annals of Internal Medicine. Retrieved from http://annals.org/article.aspx?articleid=2430211.

Kruse, G. R., Rigotti, N. A., Raw, M., McNeill, A., Murray, R., Piné-Abata, H. et al. (2015). Tobacco Dependence Treatment Training Programs: An International Survey. Nicotine \& Tobacco Research, first published online June 27, 2015 doi:10.1093/ntr/ntv142. 
Leischow, S. J., Ayo-Yusuf, O., \& Backinger, C. L. (2013). Converging research needs across framework convention on tobacco control articles: Making research relevant to global tobacco control practice and policy. Nicotine \& Tobacco Research, 15(4), 761-766. Retrieved from http://www.ncbi.nlm.nih.gov/pubmed/22990225.

Lopez, A. D., Collishaw, N. E., \& Piha, T. (1994). A descriptive model of the cigarette epidemic in developed countries. Tobacco Control, 3, 242-247.

Maziak, W., Eissenberg, T., \& Ward, K. D. (2005). Patterns of waterpipe use and dependence: implications for intervention development. Pharmacology, Biochemistry Behavior, 80(1), 173-9.

Maziak, W., Taleb, Z. B., Bahelah, R., Islam, F., Jaber, R., Auf, R. et al. (2015). The global epidemiology of waterpipe smoking. Tobacco Control, 24(suppl 1), i3-i12.

McRobbie, H., Raw, M., \& Chan, S. (2013). Research priorities for article 14-demand reduction measures concerning tobacco dependence and cessation. Nicotine \& Tobacco Research, 15(4), 805-816.

National Academies. (2015). Partnership for enhanced engagement in research (PEER). Retrieved from http://sites. nationalacademies.org/pga/peer/index.htm.

National Cancer Institute. (1991). Strategies to control tobacco use in the United States: A blueprint for public health action in the 1990's (Smoking and Tobacco Control Monograph No. 1. NIH Publication No. 92-3316). Retrieved from http://cancercontrol.cancer.gov/brp/tcrb/monographs/1/ index.html.

National Cancer Institute. (2005). ASSIST: Shaping the future of tobacco prevention and control (Tobacco Control Monograph No. 16, NIH Publication No. 05-5645). Bethesda, MD: U.S. Department of Health and $\mathrm{Hu}-$ man Services, National Institutes of Health, National Cancer Institute. Retrieved from http://cancercontrol. cancer.gov/brp/tcrb/monographs/16/m16_complete.pdf.

National Cancer Institute. (2007). Promoting healthy lifestyles: Policy, program and personal recommendations for reducing cancer risk. President's Cancer Panel, 2006-2007 annual report. Bethesda, MD: U.S. Department of Health and Human Services, National Institutes of Health, National Cancer Institute; 2007. Retrieved from http:// deainfo.nci.nih.gov/advisory/pcp/annualReports/pcp07rpt/ pcp07rpt.pdf.

National Cancer Institute and Centers for Disease Control and Prevention. (2014). Smokeless tobacco and public health: A global perspective. Bethesda, MD: U.S. Department of Health and Human Services, Centers for Disease Control and Prevention and National Institutes of Health, National Cancer Institute. NIH Publication No. 14-7983. Retrieved from http://cancercontrol.cancer.gov/brp/tcrb/global-perspective/ index.html.

Nazar, G. P., Lee, J. T., Glantz, S. A., Arora, M., Pearce, N., \& Millett, C. (2014). Association between being employed in a smoke-free workplace and living in a smoke-free home: Evidence from 15 low and middle income countries. Preventive Medicine, 59, 47-53.
Ng, M., Freeman, M. K., Fleming, T. D., Robinson, M., DwyerLindgren, L., Thomson, B. et al. (2014). Smoking prevalence and cigarette consumption in 187 countries, 19802012. JAMA: The Journal of the American Medical Association, 311(2), 183-192.

Nichter, M., Greaves, L., Bloch, M., Paglia, M., Scarinci, I., Tolosa, J. E. et al. (2010). Tobacco use and secondhand smoke exposure during pregnancy in low- and middleincome countries: The need for social and cultural research. Acta Obstetricia et Gynecologica Scandinavica, 89(4), 465477.

Obeidat, N. A., Ayub, H. S., Bader, R. K., Shtaiwi, A. S., Shihab, R. A., Habashneh, M. A. et al. (2015). Public support for smoke-free policies in Jordan, a high tobacco burden country with weak implementation of policies: Status, opportunities, and challenges. Global Public Health., Aug 7, 1-13. [Epub ahead of print].

Parascandola, M. J. (2011). Tobacco harm reduction and the evolution of nicotine dependence. American Journal of Public Health, 101, 632-641. doi: 10.2105/AJPH.2009. 189274.

Peters, D. H., Garg, A., Bloom, G., Walker, D. G., Brieger, W. R., \& Rahman, M. H. (2008). Poverty and access to health care in developing countries. Annals of the New York Academy of Sciences, 1136, 161-171.

Peto, R., Darby, S., Deo, H., Silcocks, P., Whitley, E., \& Doll, R. (2000). Smoking, smoking cessation, and lung cancer in the UK since 1950: Combination of national statistics with two case-control studies. British Medical Journal, 321(7257), 323-329.

Piné-Abata, H., McNeill, A., Murray, R., Bitton, A., Rigotti, N., \& Raw, M. (2013a). A survey of tobacco dependence treatment guidelines in 121 countries. Addiction, 108(8), 1470-75.

Piné-Abata, H., McNeill, A., Murray, R., Bitton, A., Rigotti, N., \& Raw, M. (2013b). A survey of tobacco dependence treatment services in 121 countries. Addiction, 108(8), 1476-84.

Ponder, P., Jefferson, A. M., Backinger, C., \& Grana, R. (2007). Tobacco-related research funding at the National Cancer Institute: Portfolio analysis, fiscal year 2003. Nicotine \& Tobacco Research, 10, 1053-1057.

Primack, A., Bloch, M., Haverkos, L., Gust, S., Hare, M., \& Smith, R. (2006). Launching the fogarty international center international tobacco control research and training program. Tobacco Control, 15(suppl 1), i1-i2.

Raw, M., \& Slevin, C. (2007). A survey of tobacco dependence treatment guidelines and systems in 45 countries. Retrieved from http://www.treatobacco.net/en/ uploads/documents/Publications/Raw\%20\&\%20Slevin\% 202007\%20survey\%20on\%20treatment\%20guidelines\% 20 and $\% 20$ services $\% 20$ in $\% 2045 \% 20$ countries.pdf.

Rodriguez, D., Carlos, H. A., Adachi-Mejia, A. M., Berke, E. M., \& Sargent, J. D. (2013). Predictors of tobacco outlet density nationwide: A geographic analysis. Tobacco Control, 22, 349355.

Schneider, S., \& Gruber, J. (2013). Neighbourhood deprivation and outlet density for tobacco, alcohol and fast food: First 
hints of obesogenic and addictive environments in Germany. Public Health Nutrition, 16, 1168-1177.

Stanfill, S. B., Connolly, G. N., Zhang, L., Jia, L. T., Henningfield, J. E., Richter, P. et al. (2011). Global surveillance of oral tobacco products: Total nicotine, unionised nicotine and tobacco-specific N-nitrosamines. Tobacco Control, 20(3), e2.

Syed, S. B., Dadwal, V., Rutter, P., Storr, J., Hightower, J. D., Gooden, R. et al. (2012). Developed-developing country partnerships: Benefits to developed countries?. Globalization and Health, 8, 17.

Thun, M., Peto, R., Boreham, J., \& Lopez, A. D. (2012). Stages of the cigarette epidemic on entering its second century. Tobacco Control, 21, 96-101. doi:10.1136/tobaccocontrol2011-050294.

U.S. Food and Drug Administration. (2011). Required warnings for cigarette packages and advertisements, Final Rule. June 22, 2011. 21 CFR Part 1141, Federal Register, 2011-15337. Retrieved from http://www.regulations. gov/\#!documentDetail;D=FDA-2010-N-0568-0251.

Varmus, H., \& Kumar, H. S. (2013). Addressing the growing international challenge of cancer: A multinational perspective. Science Translational Medicine, 5, 175cm2. doi: 10.1126/scitranslmed.3005899.

Varmus, H., \& Trimble, E. L. (2011). Integrating cancer control into global health. Science Translational Medicine, 3(101), $101 \mathrm{~cm} 28$.

Ward, K. D., Siddiqi, K., Ahluwalia, J. S., Alexander, A. C., \& Asfar, T. (2015). Waterpipe tobacco smoking: The critical need for cessation treatment. Drug and Alcohol Dependence, $153,14-21$.

Warner, K. E. (2005). The role of research in international tobacco control. American Journal of Public Health, 95, 976-84.

Warren, C. W., Jones, N. R., Chauvin, J., Peruga, A., \& GTSS Collaborative Group. (2008). Tobacco use and cessation counselling: Cross-country. Data from the Global Health Professions Student Survey (GHPSS), 2005-7. Tobacco Control, 17(4), 238-247.

West, R., Raw, M., McNeill, A., Stead, L., Aveyard, P., Bitton, J. et al. (2015). Health-care interventions to promote and assist tobacco cessation: A review of efficacy, effectiveness and affordability for use in national guideline development. Addiction, 10(9), 1388-1403.

WHO Study Group on Tobacco Product Regulation (TobReg). (2015). Advisory note: Waterpipe tobacco smoking: health effects, research needs and recommended actions for regulators. (2nd ed.) Geneva: World Health Organization.

World Health Organization. (1992). Women and tobacco. Geneva: World Health Organization. Retrieved from: http:// apps.who.int/iris/bitstream/10665/37510/1/9241561475_ eng.pdf
World Health Organization. (2008). Guidelines for implementation of Article 5.3 of the WHO Framework Convention on Tobacco Control. Geneva: World Health Organization. Retrieved from: http://www.who.int/fctc/guidelines/ article_5_3.pdf?ua=1.

World Health Organization. (2013a). Global action plan for the prevention and control of noncommunicable diseases, 2013-2020. Retrieved from http://apps.who.int/iris/ bitstream/10665/94384/1/9789241506236_eng.pdf?ua=1.

World Health Organization. (2013b). WHO recommendations for the prevention and management of tobacco use and secondhand smoke exposure in pregnancy. Geneva: World Health Organization. Retrieved from http://apps.who.int/iris/ bitstream/10665/94555/1/9789241506076_eng.pdf?ua=1.

World Health Organization. (2013c). WHO report on the global tobacco epidemic, 2013: enforcing bans on tobacco advertising, promotion and sponsorship. Geneva: World Health Organization. Retrieved from http://apps.who.int/ iris/bitstream/10665/85380/1/9789241505871_eng.pdf? $\mathrm{ua}=1$.

World Health Organization. (2014). Systematic review of the link between tobacco and poverty. Geneva: World Health Organization. Retrieved from http://apps.who.int/iris/ bitstream/10665/136001/1/9789241507820_eng.pdf?ua=1\& ua $=1$.

World Health Organization. (2015a). State-level laws banning gutka are impacting product availability and use. Retrieved from http://www.searo.who.int/india/mediacentre/ releases/2014/gutka_study/en/.

World Health Organization. (2015b). Tobacco free initiative: MPOWER [web page]. Retrieved from http://www.who. int/tobacco/mpower/en/.

World Health Organization. (2015c). WHO report on the global tobacco epidemic, 2015: Raising taxes on tobacco. Geneva: World Health Organization. Retrieved from http://apps. who.int/iris/bitstream/10665/178574/1/9789240694606_ eng.pdf?ua $=1$.

World Health Organization. (2015d). World Health Statistics, 2015. Geneva: World Health Organization. Retrieved from http://www.who.int/gho/publications/world_health_ statistics/EN_WHS2015_Part2.pdf?ua=1.

World Health Organization. (2015e). Tobacco, WHO Fact sheet N 339. Geneva: World Health Organization. Retrieved from http://www.who.int/mediacentre/factsheets/fs339/en/.

Yach, D., Pratt, A., Glynn, T. J., \& Reddy, K. S. (2014). Research to stop tobacco deaths. Globalization and Health, 10, 39. doi: 10.1186/1744-8603-10-39.

Yerger, V. B., Przewoznik, J., \& Malone, R. E. (2007). Racialized geography, corporate activity, and health disparities: Tobacco industry targeting of inner cities. Journal of Health Care for the Poor and Underserved, 18(4 suppl), 10-38. 